\title{
Spectra from Foil-Excited Molybdenum Ions
}

B. M. Johnson and K. W. Jones

Brookhaven National Laboratory, Upton, New York 11973

J. L. Cecchi

Plasma Physics Laboratory, Princeton University, Princeton, New Jersey 08540

T. H. Kruse

Rutgers University, New Brunswick, New Jersey 08903

Presented at

Fifth Conference on Application of Small Accelerators

November 6,7 , and 8,1978

North Texas State University

Denton, Texas 76203

This report was prepared as an account of work sponsored by the United States Government. Neither the United States nor the United States Department of Energy, nor any of their employees, nor any of their contractors, subcontractors, or their employees, makes any warranty, express or implied, or assumes any legal liability or responsibility for the orcuracy, completene or usefulness of any information, apparatus, product or usefulness of any information, apparatus, product or
process disclosed, or represents that its use would not infringe privately owned rights.
inf

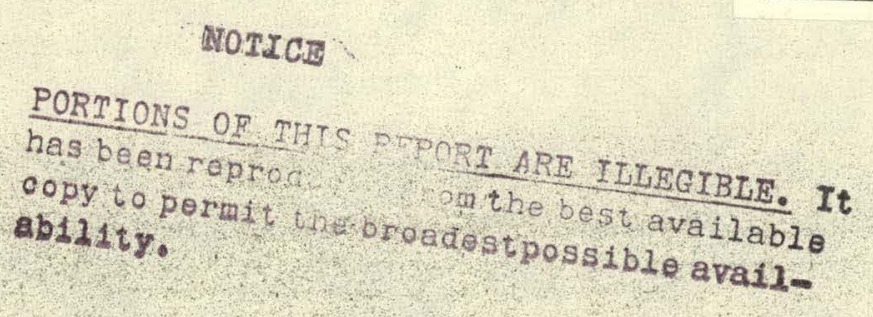

The submitted manuscript has been authored under contract EY-76-C-02-0016 with the Division of Basic Energy Sciences, U.S. Department of Energy. Accordingly, the U.S. Government retains a nonexclusive, royalty-free Ticense to publish or reproduce the published form of this contribution, or allow others to do so, for U.S. Government purposes. 


\section{DISCLAIMER}

This report was prepared as an account of work sponsored by an agency of the United States Government. Neither the United States Government nor any agency Thereof, nor any of their employees, makes any warranty, express or implied, or assumes any legal liability or responsibility for the accuracy, completeness, or usefulness of any information, apparatus, product, or process disclosed, or represents that its use would not infringe privately owned rights. Reference herein to any specific commercial product, process, or service by trade name, trademark, manufacturer, or otherwise does not necessarily constitute or imply its endorsement, recommendation, or favoring by the United States Government or any agency thereof. The views and opinions of authors expressed herein do not necessarily state or reflect those of the United States Government or any agency thereof. 


\section{DISCLAIMER}

Portions of this document may be illegible in electronic image products. Images are produced from the best available original document. 


$$
\text { J.L. Ceccini }
$$

Plasma Physics Laboratory, Princeton Unfversity, Princeton, New Jersey 08540

$$
\text { T.H. Kruse }
$$

Rutgers University, New Brunswiok, New Jersey 08903.

\section{Abstract}

The extreme-ultra-violet spectra $(5-55 \mathrm{~nm})$ for foil-excited molybdenum ions have been measured using 22-200 MeV beams from the Brookhaven National Laboratory MP tandem Van de Graaff accelerator facility, $20 \mathrm{Hg} / \mathrm{cm}^{2} \mathrm{C}$ stripping foils, and a grazing incidence spectrometer. The mean ion charge states (13 to 28) and the narrow distribution widths (about 2 charge states) were accurately predictable from experimental parameters. Where possible, comparisons are given with Mo radiation from tokamaks, vacuum sparks, and laser-excited plasmas.

\section{Introduction}

Heavy metals such as molybdenum are commonly used in the construction of tokamak devices because of their desirable physical or chemical properties. During a plesma discharge, however, these heavy atoins are released by sputtering or evaporation and have detrimental effects or plasma behavior. ${ }^{1}$ Heavy impurities cause increased bremstrahlung and recombination radiation and, in the case of specles not fully strlpped, line radiation. In order to measure absolute concentrations of these ions it is necessary to have for a particular ionic species, lines which are identifted and have lenown absorption escillator strengths. The identifisation and subsequent analysis of radlation

- from individual states of particular tons is hampered by the presence of many ionization states of several impurity elements. For example, a typical tokamak discharge can contain highly ionized io or w from current aperture limiters, $\mathrm{Cr}, \mathrm{Fe}, \mathrm{Ni}$ (stainless steel) from vacuum vessel walls and in addition to the working zas ( $\mathrm{H}$ or Fe) some light impurities such as 0 or $C$. Many other metals (e.g., Ti, Zr, Nb, Ta, Re, Pt) are under consideration as construction materials and various light ions and high-2 metals can be injected to study impurity behavior. Although many light and some medium- $Z$ elements have been extensively studied, data is needed for heavier atoms such as Mo and $W$.

The use of bean foil spectroscopy (BFS) to determine absorption oscillator strengths ( $f$ values) for light lons has been reviewed by wiese and Younger ${ }^{2}$ and recent resuits for heavfer ions are given elsewhere. 3 It has 21 so been shown 3,4 that BFS can be used to heip identify the radiating ions, stages of ionization and types of transitions for tungsten and gold contaminants in tokamak plasmas. Discrepancies between spectra from ormak 5 and PLT ${ }^{6}$ in the wavelength region from $4-8 \mathrm{~nm}$ were resolved, average charge states were indicated, and spectral features were assigned primarily to $4 d-4 f$ transitions. Further anaIysis of these spectra was prevented by the large number of overlapping iines and the scarcity of previous experimental and theoretisal work.

Ho radiation from tokamaks, vacuum sparks, and laser-exeited plasmas has besn studied spectroscopically, but usually over limited wavelength regions. We have undertaken the present study to complement the previous investigations by providing Mo spectra over an extended wavelength region $(5-55 \mathrm{rm})$ and for known enarge states and narrow distribution widths.

\section{Experimental Method}

Molybdenum beams with energies of $22,30,67,97$, 168 , and $200 \mathrm{MeV}$ were produced with the Bivi three-stage MP tandem Van de Graaff accelerator facility. The maximum bean current that was delivered to the experimental area was $6 \times 10^{9}$ particles/sec through a $3 \mathrm{~mm}$ defining aperture. Carbon stripping foils of 20 $\mu \mathrm{g} / \mathrm{cm}^{2}$ were used. The folis were thick enough to ensure charge equilibrium, but thin enough to ensure that multiple scattering was negligible. Mean charge states $\bar{q}$ for foil-excited lons are accurately predictable from experimental parameters using the formula of Nikolaev and Dimitriev 7 as confirmed by Betz. 8 The beam was collected in a Faraday cup $20 \mathrm{~cm}$ downstrean from the foil. The number of collected particles, which was determined from the accumulated charge divided by $\vec{q}$, was used to normalize the data. The full-width-at-half-maximum (FWHM) of the charge state distribution at each energy was about 2 charge states and has an approximately Gaussian shape.7

Extreme-ultra-violet (aUV) radiation emitted by the beam after passage through the stripping foil was examined with a 2.2 on grazing incidence spectrometer (Minuteman model 322G). The angle of observation was $90^{\circ}$ to the incident beam with the spectrometer entrance slits $4 \mathrm{~cm}$ from the beam axis. Radiation was dispersed with a gold-coated concave grating with 300 grooves/mm, a blaze angle of $2^{\circ} 13^{\circ}$ and a corresponding blaze wavelength of $29 \mathrm{~nm}$ at the $37^{\circ} \mathrm{grazing}$ angle used in the present work. Spectrometer entrance and exit slit widths of $300 \mu \mathrm{m}$ were used to obtain resonable signal strength. Under these conditions the spectral resolution obtained was about $0.4 \mathrm{~mm}$ FWH, and the uncertainty in the determination of the centroid of well-resolved peaks was about $0.02 \mathrm{~nm}$. The EUV radiation was detected with a channeltron electron multiplier (CEM) which had a dark current counting rate of $0.2 \mathrm{kz}$. The data were corrected for this background contribution. Spectral scans were recorded in the wavelength region from 5 to $55 \mathrm{~nm}$.

\section{Experimental Resuits and Discussion}

The results of the experiment are shown in Fig. 1. The mean charge states $\bar{q}$ of the foil-excited molybdenum fons ranged from 13 to 28 , that is, spectra with most probable ionization states ranging from zinc-like to silicon-like were observed. The most striking feature of these scans is the obvious great complexity of the broad spectral features observed. Only in a few cases, notably for $\bar{q}=13$, are strong single lines observed. Bands of lines are seen to be centered at about $8.5,18,25,35$ and $42.5 \mathrm{~nm}$. The last three show some evidence for individual lines which decrease in intensity as the mean charge state increases and are virtually gone at $\bar{q}=23$ and greater. The other two features show maxima at $\bar{q}=$ 20 , but remain as the dominant feature of the spectra through $\bar{q}=28$.

Resonance lines from copper- and zinc-like molybuenum have been observed in tokamaks ${ }^{\prime}$ and a precision measurement of their wavelengths has been made by Reader and Acquistag in a low-inductance 
spark experiment, in which the wavelengths of the $4 s^{2} s_{1 / 2}-4 p^{2} p_{1 / 2,3 / 2}$ transitions of copper-iike Mo $\mathrm{XIV}(\mathrm{q}=13)$ were measured to be 42.3576 and 37.3647 $\mathrm{nm}$, respectively, and the $4 \mathrm{~s}^{2} \mathrm{SO}_{0}-4 \mathrm{~s} 4 \mathrm{p} \mathrm{S}_{1}$ transition in zinc-iike to XIII $(q=12)$ was observed at $34.0909 \mathrm{~nm}$. The $37.4 \mathrm{~mm}$ line is clearly observed here in the $\bar{q}=13$ soectrum, and partially resolved ines aiso zppear at wivelengths of 42.4 and $34.1 \mathrm{~nm}$ in good agreement with the observations from the spark source ${ }^{9}$ and tokamak 1 experiments.

For higher $\bar{q}$, detailed comparisons with other experimental results obtained with spark sources or laser-excited plasmas are difficult because (a) spectral features are complex with few, if any, well-resolved lines; (b) there are differences in resolution, knowledge of charge states distributions, and spectrometer efficiencles; (c) there are differences in excitation mechanisms; and (d) few complete spectra have been displayed. Mansfield et al. 10 make the point that inner-subshell excitation is of

$8-1279-78$

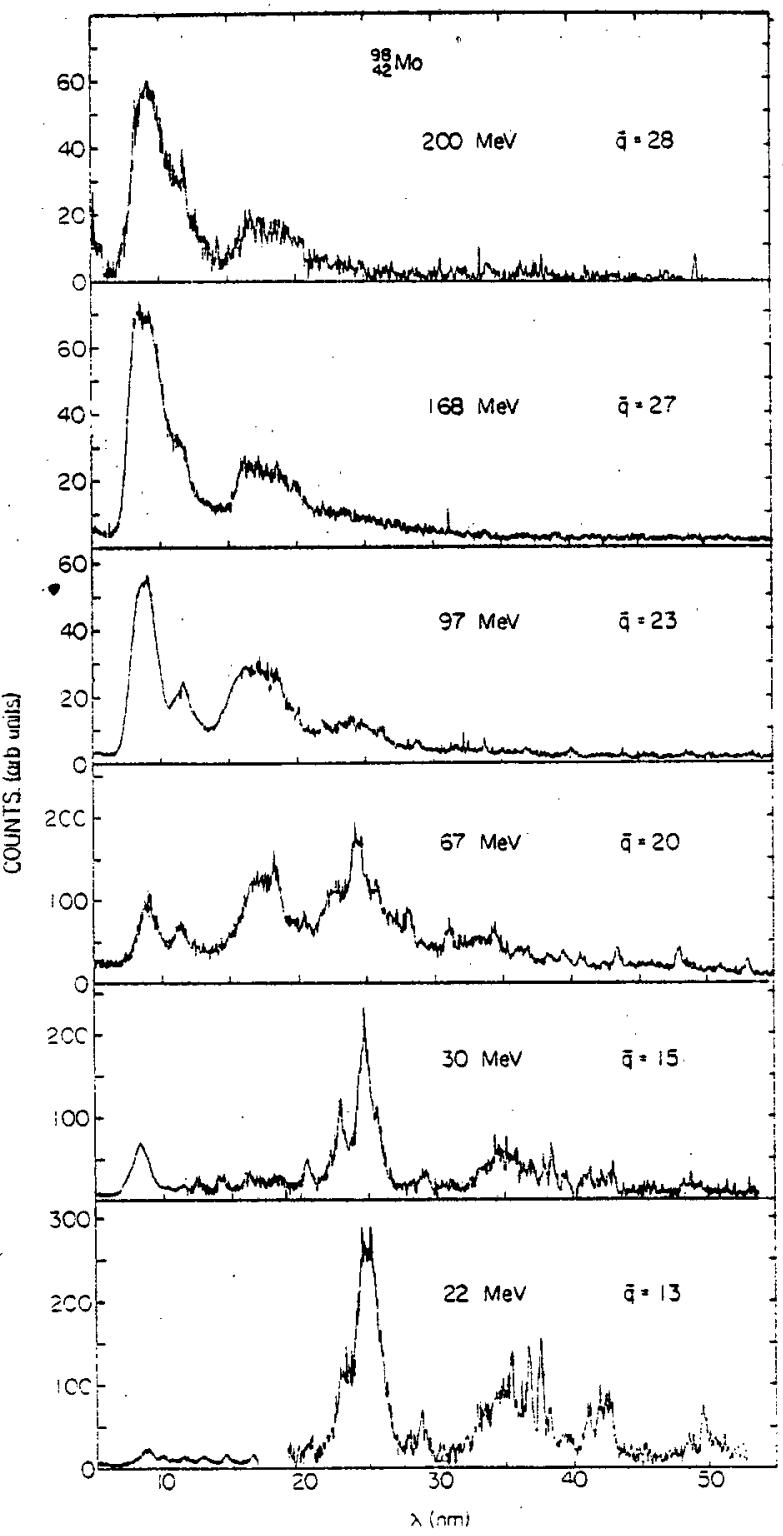

Fig. 1. Survey of foil-excited to spectra for mean charge states $\bar{q}$ between 13 and 28 . The beam energy used to produce each $\bar{q}$ is shown. importance in dense plasmas and gives greatly incraased spectral complexity. This observation is in agreenent with the BFs results shown in Fiz. 1 where the ion-atom collisions are known to produce inner-subsheil and multiple excitation.

Comparisons with theory must also be qualitative since no theoretical predictions are available which predict transition probabilities for all the very complex configurations which contribute to the experimental spectra. Curtis et al.11 in an extensive analysis of Mo XIV spectra from i vacuum spark give theoretical values for the transition probabilities. Major strength is observed at about 9 , $12,18,23,38$, and $42 \mathrm{~nm}$, which is in reasonabla agreement with the present experimental spectrum for $\bar{q}=13$. A more detalled comparison would require correction of the experimental results for the wavelength dependence of the spectrometer efficiency and extension of the calculated transition probabilities to other charge states. Perhaps a more favorable possibility for comparison of theory and experiment is in the 5-50 nm region for $\bar{q}=27$ or 28 . Theoretical calculations for $E i$ transitions have been made by Cowan 12 for charge states from 24 to 37 . The major strength observed in the highest energy spectra of E1g. 1 is concentrated in the region from 8 to $10 \mathrm{~nm}$ which is in good agreement with the theoretical prediction.

Finally, we compare our results with observations of molybdenum excited in tokamak plasmas. Although no published spectra are available, Hinnov 1 has reported observation of the $\mathrm{Cu}$ - and $\mathrm{Zn}$ - like lines whose wavelengths were confirmed by Reader and Acquista. 9 Hinnov also observed radiation attributed to states of ionization higher than covered in the present experiment. The TFR group has reported rather extensive work on Mo, mainly on these higher lonization states and on forbidden lines. 13,14 Geller et al. 15 haye reported observation on Alcator of a series of lines with a peak between 6.4 and $9 \mathrm{~nm}$, which is somewhat lower than observed here. The reason for this discrepancy is unknown.

\section{Cenclusions}

It has been shown here that it is possible to obtain beam-foil spectra of nolybdenum in charge states which cover a region of current interest in tokamak applications. The complexity of the spectra suggest that theoretical predictions of averaze spectral behavior would be more useful rather than to attempt to resolve each line experimentally. The beam-foll excitation method is of great value in detamining the charge state dependence of the spectra and in the future will be able to give lifetime information unobtainable by other means.

\section{Acknowledgements}

We acknowledge the capable assistance of $\mathrm{G}$. Humer, P. Thieberger, R. Lindgren and the rest of the Brookhaven tandem operations group.

Work supported by the Division of Basic Energy Sciences, U.S. Department of Energy, under Conttract No. EY-76-C-02-0016.

\section{References}

i. E. Hinnov, Phys. Rev. A 14, 1533 (1975). 
$4 ?$

2. W.L. Wiese and S.M. Younger, Beam zo1h SpectrosCopy, Vol. 2, Eds. I.A. Sell in and D.J. Pegg, (Plenum, New York, 1976), p. 951.

3. B.M. Jonnson, Proceedings of this conference.

4. B.M. Jonnson, K.W. Jones, J.i. Cecchi, E. Hinnov and T.H. Kruse, PPPL-1479 (1979); to be published.

5. R.C. isler, R.V. Neidigh and R.D. Cowan, Phys. Lett. $63 \mathrm{~A}, 295$ (1977).

6. E. Hinnov and H. Mattioli, Phys. Lett. A66, 109 (1978).

7. v.S. Nikolaev and I.S. Dimitriev, Phys. Lett. 2BA, 277 (1968).

8. H. Betz, Rev. Mod. Phys. 44,465 (1972).'

9. J. READER AND eader and N: Acquista, Phys. Rev. Lett. 39, 184 (1977).

10. M.W.D. Mansfleld, N.J. Peacock, C.C. Smith, M.G. Hobby, and R.D. Cowan, J. Phys. B LI, 1521 (1978).

11. L.J. Curtis, A. Lindgard, B. Edlen, I. Martinson, and S.E. Nielsen, Phys. Scr. 16, 72 (1977).

12. R.D. Cowan, LASC Report: LA-6679-MS (1977). (National Technisal Information Service, Springfield, Virginia, 1977).

13. J.L. Sehwob, M. Klapisch, N. Schweitzer, M. Finkenthal, $C$. Breton, $C$. DeMichelis, and $M$. Matt1011, Phys. Lett. 62A, 85 (1977).

14. M. Klapisch, J.L. Schtob, M. Finkenthal, B.S. Fraenkel, S. Egert, A. Bar-Shalom, C. Breton, C. Deilichelis, and M. Mattioli, Phys. Rev. Lett, 41, $403(1978)$.

i5. R. Geller, Z.s. Marmar, and K.I. Chen, Bull. Am. Phys. Soc. 22, 1147, (1977). 